\title{
The U.S. Investment Tax Credit for Solar Energy: Alternatives to the Anticipated 2017 Step-Down
}

\author{
Stephen Comello* \\ Graduate School of Business \\ Steyer-Taylor Center for Energy Policy and Finance \\ Stanford University \\ and \\ Stefan Reichelstein \\ Graduate School of Business \\ Steyer-Taylor Center for Energy Policy and Finance \\ Stanford University
}

July, 2015

\footnotetext{
*Contact information: scomello@stanford.edu; reichelstein@stanford.edu We gratefully acknowledge financial support from the Steyer-Taylor Center for Energy Policy and Finance and a U.S. Department of Energy (DOE) grant administered through the Bay Area Photovoltaics Consortium (BAPVC). We also thank Dan Reicher and Felix Mormann for their comments and suggestions. Any errors or omissions are our own.
}

(C) 2015. This manuscript version is made available under the Elsevier user license http://www.elsevier.com/open-access/userlicense/1.0/ 


\begin{abstract}
Solar photovoltaic (PV) installations in the United States have been deployed at a rapid pace in recent years, a development that is attributed in significant part to the federal Investment Tax Credit (ITC). Yet, this credit is scheduled to step-down from $30 \%$ to $10 \%$ at the beginning of 2017 for corporate investors. For a sample of five U.S. states and different segments of the solar industry, we find that the anticipated ITC step-down in 2017 would increase the levelized cost of solar power by a significant margin, raising the specter of a 'cliff' for the solar industry. Our analysis identifies and evaluates an alternative phase-down scenario that would reduce the ITC gradually over time and eliminate it completely by 2024. For this alternative phase-down scenario, it is shown that solar PV would remain broadly competitive, provided the solar industry can maintain the pace of cost reductions demonstrated in past years.
\end{abstract}

\title{
Keywords
}

Solar energy

Cost competitiveness

Levelized cost

Tax incentives 


\section{Introduction}

Solar power has experienced remarkable growth in the United States in recent years. To illustrate, $105 \mathrm{MW}$ of photovoltaic (PV) installations were added at an average system price of $\$ 7.90$ per Watt in 2006. In 2013, 4,776 MW of new PV capacity were installed an average system price of $\$ 2.93$ per Watt. By 2014, new solar installations did account for more than one third of all newly installed capacity for electricity generation in the U.S. (GTM Research, 2014). Tax incentives have arguably had a significant role in initiating this growth, specifically the $30 \%$ federal Investment Tax Credit (ITC) in conjunction with the accelerated depreciation tax shield provided through the Modified Accelerated Cost-Reduction System. Current legislation, though, stipulates that the ITC for solar installations will be 'stepped down' from its current $30 \%$ rate to $10 \%$ on January 1, 2017 . $^{1}$

This paper assesses the impact of the anticipated ITC step-down on the competitiveness of solar energy across different locations and different segments of the U.S. solar industry. As an alternative to the anticipated step-down, we evaluate a gradual 'phase-down' scenario. Our analysis focuses on five key states: California, Colorado, New Jersey, North Carolina and Texas. These sample states not only account for more than $65 \%$ of the cumulative solar installations in the U.S., they also exhibit considerable diversity in terms of solar energy market maturity, insolation rates, labor/material costs, and market structure. For each state, our analysis considers three market segments: residential rooftop $(<10 \mathrm{~kW}$ capacity per installation), commercial-scale $(10 \mathrm{~kW}-1000 \mathrm{~kW})$ and utility scale $(>1 \mathrm{MW})$. For utility-scale systems, we distinguish between two technology platforms: c-Si (crystalline silicon) and CdTe (thin film) solar cells. Taken together, our calculations thus cover $5 \times 4=20$ separate settings.

Our main metric for assessing the cost competitiveness of solar PV under different policy regimes is the Levelized Cost of Electricity (LCOE). The LCOE identifies the break-even value that a power producer would need to obtain on average per kilowatt-hour (kWh) as revenue in order to justify an investment in a particular power generation facility. We calculate LCOEs by segment and by state, taking a "bottom-up" cost estimation approach.

\footnotetext{
${ }^{1}$ See 26 USC §25D and 26 USC §48. The ITC was initially created as part of the Energy Policy Act of 2005 and extended through the end of 2016 with the Emergency Economic Stabilization Act of 2008. Our analysis focuses exclusively on the tax credits available in connection with corporate income taxes. The $30 \%$ ITC is currently also available for individual taxpayers, yet this credit is scheduled to expire entirely by early 2017.
} 
Accordingly, we estimate the cost of each solar energy system subcomponent, with the aggregate then providing the initial (2014) estimate for both the system price and the applicable operations- and maintenance costs. To assess cost competitiveness, the LCOE is considered relative to a comparison price that is applicable for a particular segment in a specific state. For commercial-scale installations in Colorado, for instance, the comparison price is given by the average rate charged per $\mathrm{kWh}$ to commercial users by energy service providers in Colorado.

Ignoring any state-level incentives, the following findings emerge at 2014 costs with a $30 \%$ ITC : (i) utility scale installations are not yet cost-competitive across the entire spectrum of states considered when the LCOE of these installations is compared to the wholesale price of electricity, (ii) Commercial-scale installations are currently well positioned in California and marginally competitive in Colorado and Texas when their LCOE is compared to the average commercial retail electricity rates in those states (iii) Residential installations are comfortably competitive in California, breaking-even in Colorado and North Carolina, but not yet competitive in Texas and New Jersey when compared with retail rates, under the assumption that there are no restrictions on net energy metering.

To project cost reductions in the future, we forecast the LCOE for individual segments and states by applying a cost dynamic to the individual components of solar PV systems. For PV modules, we rely on a model of economically sustainable prices based on production cost fundamentals of the upstream manufactures. For inverters, balance of system (BOS) and operations and maintenance costs, we estimate exponential decay functions, the latter two adjusted for state-level differences in component costs. In all cases, these component costs are assumed to decrease with time due to efficiency gains and accumulated experience. ${ }^{2}$ The rate of change at which BOS costs decrease is specific to the segment and geography reflecting local market conditions for labor and materials materials.

While the expected magnitude of further reductions in system prices for solar PV is significant, we nonetheless find that if the step-down to a $10 \%$ ITC were indeed to occur at the beginning of 2017, solar PV would become uncompetitive essentially across the entire

\footnotetext{
${ }^{2}$ Our cost reduction assumptions for PV modules are based on a standard learning-by-doing model in which cumulative production volume is the explanatory variable. Since PV modules are a global commodity, the pace of future production volumes is arguably not affected materially by our analysis of alternative scenarios in the U.S., as the overall share of modules installed in the U.S. is less than $10 \%$ of the worldwide production volume.
} 

step-down in the ITC is likely to result in a 'cliff' for the U.S. solar industry in early 2017. At the same time, the sustained reduction in PV system costs demonstrated over the past decades suggests that, in order to be cost competitive, solar energy will not require an indefinite continuation of the $10 \%$ ITC. An alternative to the current tax law therefore could specify a more gradual glide path that would entail larger tax incentives than the currently specified 10\% ITC for a limited number of years in exchange for a complete elimination of the federal tax incentives at some definitive future date. The ultimate elimination of the ITC effectively introduces a quid-pro-quo element that should make the proposal more acceptable politically.

For simplicity, we evaluate a policy scenario that involves only three distinct phases, starting at the beginning of 2017, 2021 and 2025, respectively. For the first two phases, the revised tax rules are calibrated so as to result in LCOEs that are in between those corresponding to the $10 \%$ and the $30 \%$ ITC benchmarks. The impact of gradually reduced tax incentives would be partially offset by the anticipated cost reductions during the previous phase. Because smaller residential systems tend to be the most expensive on a per Watt basis, the current solar ITC provides the largest support to residential PV systems in terms of dollars per Watt installed. More flexible and targeted tax incentives can be achieved by providing investors with a choice between alternative methods for calculating the ITC.

For the years 2017 - 2020, the phase-down scenario evaluated in this paper entails a choice between a $20 \%$ ITC or a lump-sum ITC in the amount of 35 cents per Watt installed. The 35 cents figure is obtained by putting a price on the stream of future carbon emissions that would be avoided by generating electricity from solar cells rather than a state-of-the art natural gas facility. ${ }^{3}$ Consistent with the overall concept of diminishing ITC support, the second phase would cut the previous parameters in half for the years 2021 - 2024. Investors would then have the choice between a $10 \%$ ITC or a lump-sum ITC in the amount of 17.5 cents per Watt.

Our simulation results show that the proposed alternative phase-down scenario would go a long way towards avoiding the cliff that is likely to result from the currently anticipated

\footnotetext{
${ }^{3}$ For direct comparison, our LCOE figures indicate that in the current environment solar PV is not yet cost competitive with natural gas combined cycle facilities, even under ideal conditions for solar: a $30 \%$ ITC and high insolation levels. This conclusion, however, hinges on the availability of natural gas at its current low price in the U.S. (Comello and Reichelstein, 2014).
} 

calculated as a percentage of the system price. The $20 \%$ ITC for the years 2017 - 2020 would be sufficient to keep the residential segment cost competitive in most of the five states we examine. Furthermore, the anticipated additional reductions in cost are projected to leave residential installations with an LCOE that is within $10-20 \%$ of the retail rates expected for the years 2021 - 2024, in all states other than New Jersey.

Commercial and utility-scale systems would prefer the lump-sum ITC under our policy proposal. With this option, commercial-scale installations would be cost competitive in California and Texas and close to break-even in the remaining three states of Colorado, New Jersey and North Carolina during the first phase. Without any ITC, commercial installations in California and Texas are projected to be competitive by 2025, at break-even in Colorado, and at a small disadvantage in New Jersey and North Carolina. Finally, the federal tax support we envision would leave utility-scale installations with LCOE values which at least match the projected wholesale electricity prices, starting in 2018. Importantly, utility-scale installations are projected to be fully cost competitive, or close to competitive, without any ITC by 2025.

Our approach in this paper follows the lead of earlier studies that have assessed the cost competitiveness of solar PV in terms of the levelized cost of electricity; see for instance Branker, Pathak, and Pearce (2011), Reichelstein and Yorston (2013), and Hernandez-Moro and Martnez-Duart (2013). ${ }^{4}$ Earlier work on the economics of solar PV has also highlighted the magnitude of learning effects resulting in sustained cost reductions for the manufacture of solar panels, other hardware and the installation of solar systems (Moore and Post, 2008; Feldman et al., 2014; Tyagi et al., 2013). A third strand of the literature examining the deployment of solar PV has focused on the role of policy support, including the role of feedin tariffs in countries like Germany, Spain or Taiwan (del Ro and Mir-Artigues, 2012; Liou, 2015) in contrast to the investment tax credits used in the U.S. (Laird and Stefes, 2009; Reichelstein and Yorston, 2013).

The distinct approach of the present study is that it effectively solves for a declining schedule of federal tax support that would keep solar PV cost competitive over time. The parameters of the ITC phase-down are determined so as to offset the anticipated reductions in solar PV costs. If these cost reductions indeed materialize over the next decade, the levelized

\footnotetext{
${ }^{4}$ As pointed out in earlier studies, the LCOE metric is an average cost calculation that ignores the economic effects of both intermittency and real time variations in electricity prices (Joskow, 2011).
} 


\section{Assessment of Current Levelized Costs}

To examine the economics of solar PV installations for different locations and industry segments, we focus our analysis on five key states: California, Colorado, New Jersey, North Carolina and Texas. Taken together these five sample states account for over $65 \%$ of all the solar installations currently in the U.S. In addition, these states were chosen for diversity in terms of insolation factors, labor/material rates, maturity of the local solar energy industry, and prevailing electricity prices. Within each state, the industry is classified into three segments: residential rooftop ( $<10 \mathrm{~kW}$ capacity per installation), commercial-scale (10 $\mathrm{kW}-1000 \mathrm{~kW}$ ) and utility-scale installations (>1 MW). For utility-scale installations, we consider 1-axis tracking configurations, given their more favorable capacity factors using either c-Si (crystalline silicon) or CdTe (thin film) solar panels. Our analysis thus covers $5 \times 4=20$ state/segment applications.

The Levelized Cost of Electricity (LCOE) concept is commonly used in the energy literature to compare the cost competitiveness of alternative energy sources. LCOE accounts for all physical assets and resources required to deliver one unit of electricity output. Fundamentally, the LCOE is a life-cycle cost measure on a per kilowatt-hour $(\mathrm{kWh})$ basis that 
must be covered as sales revenue in order to justify an investment in a particular power generation facility. As such, the LCOE reflects the time-value of money and identifies a break-even figure that must be attained as average revenue per $\mathrm{kWh}$ in order for equity investors and creditors to attain a zero-net-present value on their investments, and thereby a competitive return on their capital. Following the approach in Reichelstein and Yorston (2013), we represent the LCOE in the form: ${ }^{5}$

$$
L C O E=f+c \cdot \Delta
$$

where

- $f$ denotes the time-averaged fixed operating and maintenance costs (in $\$$ per $\mathrm{kWh}$ )

- $c$ denotes the unit cost of capacity related to the solar system (in $\$$ per $\mathrm{kWh}$ )

- $\Delta$ represents a tax factor that captures the effect of corporate income taxes (in \%).

As presented here, the LCOE does not account for the fact that electricity prices in the wholesale market and the rates paid by commercial customers can vary considerably across the hours of the day and across different seasons. In particular, solar PV systems will frequently generate most their output at times when real-time electricity prices tend to be relatively high, thus creating a natural synergy between solar power (Joskow, 2011) and real-time electricity rates. Recent work by Reichelstein and Sahoo (2015b) identifies a multiplicative adjustment factor to the basic LCOE calculation. The adjustment factor captures any synergies that result from correlations between relatively high electricity prices and solar PV generation patterns at particular times of the day. For select locations in California, Reichelstein and Sahoo (2015b) conclude that the effective LCOE of solar installations is about $10-15 \%$ lower than suggested by a traditional LCOE analysis based only on broad averages.

Among the three components of the LCOE formula in equation (1), the unit cost of capacity, $c$, is derived primarily from the system price of the solar installation. The corresponding initial investment expenditure must be 'levelized' across the stream of future energy outputs derived from the system in order to arrive at a unit capacity cost per kWh.

\footnotetext{
${ }^{5}$ For a full treatment of the basic LCOE concept, the reader is referred to Reichelstein and Yorston (2013). See also Appendix B in the Supplementary Data for an expanded LCOE formulation.
} 
Following Reichelstein and Yorston (2013), the relationship between the unit cost of capacity and system price is given by:

$$
c=\frac{S P}{8,760 h / \text { year } \cdot C F \cdot \sum_{t=1}^{T} x_{t} \cdot \gamma^{t}},
$$

where 8760 refers to the number of hours per year and $C F$ denotes the applicable capacity factor which varies with the application according to segment and to geographic location. By $T$ we denote the useful life of the solar installation, which in all our calculations is fixed at 30 years. The parameters $x_{t}$ represent the factor of the initial capacity that is still available in year $t$ after accounting for system degradation. Our calculations generally assume a constant 0.5 percent system degradation rate. Thus, $x_{t}=.995^{t-1}$. Finally, $\gamma=\frac{1}{1+r}$ denotes the discount factor based on the applicable cost of capital $r{ }^{6}$

Since the LCOE concept takes an investor perspective, we employ a "bottom-up" cost approach to arrive at the sales price that a turnkey installer in a given state and segment would charge a would-be investor for a new solar energy system. ${ }^{7}$ The three main components for the system price are the solar module, the inverter and the balance of system (BOS):

$$
S P=P P+I P_{i}+B O S_{i j}
$$

where

- $P P$ denotes the solar PV module price (in $\$$ per Watt)

- $I P_{i}$ denotes the inverter cost for segment $i$ (in $\$$ per Watt)

- $B O S_{i j}$ denotes the Balance of system cost for segment $i$ in state $j$ (in $\$$ per Watt).

Our study views photovoltaic modules as global commodities that are not subject to price differentiation across geographies and segments within the U.S. Inverters are also viewed as

\footnotetext{
${ }^{6}$ We interpret $r$ as a weighted average cost of capital (WACC). Our analysis does not attempt a comprehensive assessment of the applicable cost of capital for the different solar PV settings we consider. For our baseline calculations, the cost of capital is held fixed at $7.5 \%$ for utility scale installations, $8 \%$ for commercial installations and $8.5 \%$ for residential systems. These specifications are arguably somewhat on the high side in the current environment of ultra-low interest rates. Section 5 below examines the sensitivity of our findings to changes in the assumed cost of capital.

${ }^{7}$ Similar to (Goodrich, James, and Woodhouse, 2012), our approach aggregates the costs of individual system components to arrive at the overall system price.
} 
commodities, though their costs differ across segments. The remaining BOS component exhibits cost differentiation across both segments and geography. BOS cost components are further classified into subcomponents including combiners, wiring, racking and mounting, structural/foundations (utility), AC interconnection, engineering/design, labor, SG\&A and margins. $^{8}$

To parameterize the model, we relied on solar PV module prices based on recent (2014) average sales prices. The estimates for current average inverter prices were determined through select interviews with industry observers and analyst reports (GTM Research, 2014; BNEF, 2014). The resulting estimates were consistent with figures reported in Barbose, Weaver, and Darghouth (2014) and Feldman et al. (2014). National averages of BOS subcomponents by segment were determined through select practitioner interviews, combined with analyst reports (Lux Research, 2013; GTM Research, 2014; NREL, 2014; SNL Financial, 2014; Feldman et al., 2014), published reports (NREL, 2014; Barbose, Weaver, and Darghouth, 2014; Feldman et al., 2014) and journal articles (Hernandez-Moro and Martnez-Duart, 2013; Branker, Pathak, and Pearce, 2011). ${ }^{9}$ With respect to operating- and maintenance costs, national averages were again determined using a bottom up approach by segment (Jordan, Wohlgemuth, and Kurtz, 2012; SNL Financial, 2014; GTM Research, 2014), using data from interviews and prior literature (Moore and Post, 2008; Tyagi et al., 2013). ${ }^{10}$

The tax factor, $\Delta$, in equation (1) reflects the impact of corporate income taxes, depreciation tax shields and investment tax credits. Absent any ITC, the tax factor amounts to a "mark-up" on the unit cost of capacity. ${ }^{11}$ While the tax factor generally exceeds 1 , it can be reduced below 1 through an ITC. Table 1 shows the impact of the ITC on $\Delta$ for two depreciation methods: the 150\% declining balance method with an assumed 20-year useful asset life and the Modified Accelerated Cost-Reduction System (MACRS), that is applicable for solar generation assets.

\footnotetext{
${ }^{8}$ This component-based approach follows the approaches in Hernandez-Moro and Martnez-Duart (2013) and Goodrich, James, and Woodhouse (2012).

${ }^{9}$ These national averages were then adjusted using the RSMeans City Cost Indexes (RSMeans, 2014) to reflect labor, material and overhead costs in specific locations. The cities used to adjust national BOS subcomponent costs to state BOS subcomponent costs are: Fresno (CA), Boulder (CO), Atlantic City (NJ), Charlotte (NC) and Austin (TX).

${ }^{10} \mathrm{O} \& \mathrm{M}$ costs include module replacement, inverter replacement, general maintenance and an escalation factor. Like BOS, these were then adjusted for geography using appropriate City Cost Indexes. For detailed information on initial variable values, the reader is referred to Appendix A in the Supplementary Data.

${ }^{11}$ The detailed expression for the tax factor $\Delta$ is provided in Appendix B of the Supplementary Data.
} 
Table 1: The tax factor, $\Delta$, at a blended tax rate of $\alpha=40 \%$, for different depreciation schedules and ITC values.

\begin{tabular}{lcc}
\hline \hline $\begin{array}{l}\text { Depreciation } \\
\text { Method }\end{array}$ & ITC & $\Delta$ \\
\hline 20 year; 150\% Declining Balance & $0 \%$ & 1.32 \\
MACRS & $0 \%$ & 1.12 \\
MACRS & $10 \%$ & 0.98 \\
MACRS & $30 \%$ & 0.71 \\
\hline
\end{tabular}

Since the tax factor, $\Delta$ acts as a multiplier on the unit cost of capacity, $c$, we conclude that, compared to a $0 \%$ ITC, the introduction of a 30\% ITC effectively amounts to a $37 \%$ reduction in the cost of capacity needed to generate one $\mathrm{kWh}$ of electricity. Furthermore, a $30 \%$ ITC effectively reduces the unit cost of capacity by $27 \%$ relative to a $10 \%$ ITC scenario.

Table 2: LCOE @30\% ITC $\left(L C_{30}\right)$ versus Comparison Price $(C P)$ in 2014.

\begin{tabular}{|c|c|c|c|c|c|c|c|c|}
\hline & \multicolumn{2}{|c|}{ Utility (c-Si) } & \multicolumn{2}{|c|}{ Utility (CdTe) } & \multicolumn{2}{|c|}{ Commercial } & \multicolumn{2}{|c|}{ Residential } \\
\hline & $\mathrm{LC}_{30}$ & $\mathrm{CP}$ & $\mathrm{LC}_{30}$ & $\mathrm{CP}$ & $\mathrm{LC}_{30}$ & $\mathrm{CP}$ & $\mathrm{LC}_{30}$ & $\mathrm{CP}$ \\
\hline California & 6.85 & 5.75 & 7.17 & 5.75 & 10.89 & 15.44 & 11.95 & 17.37 \\
\hline Colorado & 6.38 & 5.36 & 6.68 & 5.36 & 9.68 & 9.50 & 11.73 & 11.94 \\
\hline New Jersey & 8.59 & 6.36 & 8.95 & 6.36 & 13.52 & 12.32 & 20.88 & 15.04 \\
\hline North Carolina & 7.10 & 6.12 & 7.44 & 6.12 & 10.29 & 9.50 & 11.55 & 12.19 \\
\hline Texas & 6.69 & 4.78 & 7.03 & 4.78 & 9.61 & 9.55 & 13.31 & 10.18 \\
\hline
\end{tabular}

All figures in 2014 cents per $k W h$

Table 2 shows our LCOE estimates by segment and state for the year 2014. These estimates are contrasted with the appropriate comparison price $(\mathrm{CP})$, given by the average 


\section{$3 \quad$ Levelized Cost Dynamics}

While solar PV has yet to reach 'grid-parity' broadly, the cost reductions achieved over the past five years have been significant. The relevant question for our purposes therefore is how solar PV will be positioned at the end of 2016, when the current ITC is scheduled to step-down from $30 \%$ to $10 \%$. In addressing this question, we postulate a dynamic for the system price and operating- and maintenance costs that enables us to project future LCOE reductions.

To obtain a forecast for the evolution of PV module sales prices, we adopt the notion of economically sustainable price (ESP) in Reichelstein and Sahoo (2015a). By construction, the ESP is the expected competitive market price for modules that would result in a longrun industry equilibrium. As such, the ESP incorporates all manufacturing costs and a competitive mark-up, which reflects the required return for module producers. For a sample of publicly listed module manufacturers, Reichelstein and Sahoo (2015a) examine line items from income statements and balance sheets to infer manufacturing costs. In conjunction with industry-wide data on capacity additions and industry-wide production levels, their analysis derives an estimate for prices that should have prevailed if the industry had been in equilibrium. These estimates are shown in the green line in Figure 1 for the years 2008 - 2013. In contrast, the blue line depicts the actual sales prices (ASP). While ESPs and ASPs were closely matched until early 2011, actual sales prices began to fall more quickly thereafter. That point in time also coincides with major additions to global manufacturing

\footnotetext{
${ }^{12}$ For the five sample states considered in our study, the reader is referred to (DSIRE, 2014a), (DSIRE, 2014b), (DSIRE, 2014c), (DSIRE, 2014d) and (DSIRE, 2014e), respectively.
} 
Average Sales Prices of Modules and Cumulative Module Output

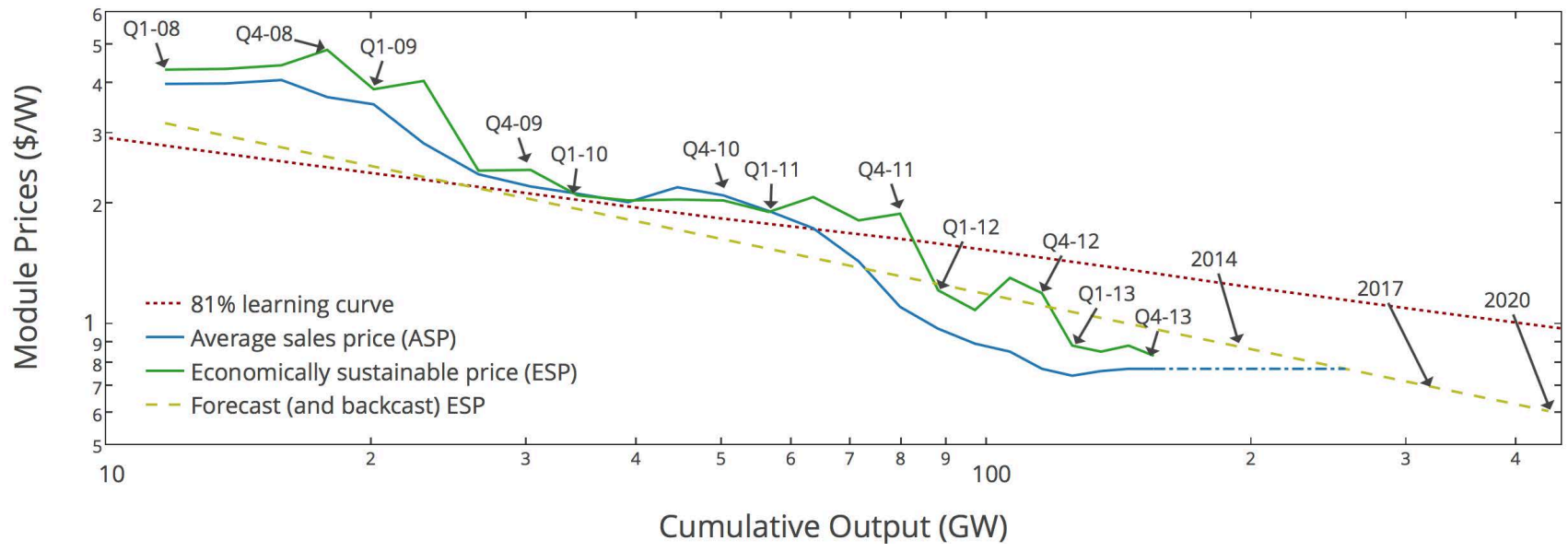

Figure 1: Historical ASP and ESP for PV modules and forecast of future ESPs.

capacity, suggesting that the sharp drop in observed average sales prices must be attributed in part to excess capacity rather than manufacturing cost reductions only.

The dashed yellow line in Figure 1 represents the fundamental trend line of regressed ESPs in Reichelstein and Sahoo (2015a). We rely on these estimates to extrapolate a trajectory of future equilibrium prices to which ASPs should converge over time. Specifically, we assume that module prices will remain flat until 2017 when ESPs are projected to catch up with current ASPs. Our calculations assume that thereafter the industry will remain in equilibrium and therefore both ASPs and ESPs will decrease at the rate depicted by the dashed yellow line. We note that this line corresponds to a $78 \%$ constant elasticity learning curve which is slightly faster than the $80 \%$ learning curve identified for solar PV modules in the earlier work of Swanson (2011). ${ }^{13}$

For inverters and BOS costs, there is less empirical evidence that these cost components fall as a function of the cumulative number of units produced or the cumulative number of solar PV systems installed. Our analysis follows prior studies that have viewed price reductions as a function of time. Specifically, an exponential decay function is used to capture the idea that these costs evolve at a rate proportional to their current value (Nemet, 2006; Neij, 2008; Ferioli and van der Zwaan, 2009). Thus,

\footnotetext{
${ }^{13}$ Our calculations are based on the the EIA's (2014) predictions regarding global production of modules. Given that trajectory, we can impute the ESPs of modules as a function of calendar time.
} 


$$
B O S(t)_{i j}=\operatorname{BOS}(0)_{i j} \cdot e^{-\lambda_{i j} \cdot t}
$$

where:

- $B O S(0)_{i j}$ denotes the cost of component $i$ in segment $j$ state at $t=0$ (i.e. 2014)

- $B O S(t)_{i j}$ denotes the cost of component $i$ in segment $j$ state and period $t$

- $\lambda_{i j}$ represents the rate of cost reduction in each period.

To project future $B O S(t)$ costs, our calculations rely on a mix of proprietary analyst reports (GTM Research, 2014; SNL Financial, 2014; Lux Research, 2013), published reports (Barbose, Weaver, and Darghouth, 2014; Feldman et al., 2014; NREL, 2014) and journal publications (Tyagi et al., 2013; Hernandez-Moro and Martnez-Duart, 2013). The arithmetic mean of each subcomponent cost per year, per segment was used to create a segment-specific national average set of BOS subcomponents. ${ }^{14}$ An exponential decay parameter, $\lambda_{i j}$ was estimated for each application. The functional form in (4) was then used to extrapolate $B O S(t)_{i j}$ for the entire period of analysis, that is the years $2014-2024$. On average, these estimations resulted in annual cost reduction factors of $5-5.2 \%, 4.2-4.4 \%$ and $3.9-4 \%$ for BOS in the residential, commercial and utility segments, respectively. For the initial values of $\operatorname{BOS}(0)_{i j}$, the reader is referred to Tables A.2 - A.4 in Appendix A in the Supplementary Data.

Inverters are considered a commodity and therefore cost differences are assumed to occur across segments but not across states (i.e. these variables are only a function of $i$, not $j$ ). Postulating again exponential decay, we have:

$$
I P(t)_{i}=I P(0)_{i} \cdot e^{-\lambda_{i} \cdot t}
$$

The same sources used in connection with BOS costs, led us to annual cost reduction estimates for inverters of $2.5 \%, 2.3 \%$ and $2 \%$ in the residential, commercial and utility segments, respectively. Taken together, the expression for the system price in equation (3) is therefore indexed to time according to:

\footnotetext{
${ }^{14}$ In order to determine state-level averages, forecasted national average subcomponent costs were adjusted using the City Cost Indexes (RSMeans, 2014), as described for current costs in Section 2 above.
} 


$$
S P(t)=E S P(t)+I P(t)_{i}+B O S(t)_{i j}
$$

Finally, operating and maintenance costs constitute a relatively small component of the LCOE (approximately 13\%). Based on analysts' reports, we assume that O\&M costs decrease at an annual rate of $5 \%$ across all applications:

$$
f(t)_{i j}=f(0)_{i j} \cdot 1.05^{-t}
$$

The preceding specifications describe the cost dynamic for the individual components of the solar system prices, which in turn determine the anticipated changes in the LCOE.

One simplification of our cost dynamic model is that reductions in cost are assumed to be a function of time only. As a consequence, our formulation ignores "endogeneity issues" that could potentially arise because different policy regimes would probably alter the path of solar deployments in the U.S. As noted above, the literature on solar PV modules generally specifies learning curves that tie cost reductions at any point in time to the cumulative volume of production up to that point in time. Yet, because there is a global industry for solar modules and U.S. demand accounts for only a small share (less than 10\%), changes in U.S. tax policy are unlikely to have a discernable effect on future module prices. Certain components of the BOS costs, e.g., permitting, will arguably decrease with cumulative experience in a particular region. For other components of the BOS costs, it seems plausible that there is innovation diffusion and firms will have access to global best practices, regardless of the rate of deployment in a particular location. 
1

3

4

5

6
7

8
9 
Table 3 shows the projected LCOE values by the end of year 2016 next to the applicable comparison prices as well as the LCOE that would be obtained at that point in time if the ITC were indeed to drop to $10 \%\left(L C O E_{10}\right)$. The main conclusion emerging from Table 3 is that the anticipated cost reductions by the end of 2016 are nowhere near sufficient to compensate for the LCOE jump associated with the anticipated drop in the ITC. To witness, our calculations indicate that, based on a $10 \%$ ITC, solar PV would not be able to match the applicable comparison prices in any of the applications we have examined, with the exception of commercial installations in California. For most of the other applications, solar PV would in fact become distinctly uncompetitive.

The magnitude of the percentage jump in LCOE is the most pronounced for the residential segment. This effect emerges because ITC tax credits are based on the fair market value of the system installed. Determination of the fair-market value is relatively straightforward if the investor and the solar developer are two separate parties that transact with each other on an arm's-length basis, as is usually the case for commercial and utility-scale solar projects. For residential systems, however, developers and investors (owners) are frequently the same party and the fair market value of the system is then obtained through one several allowable methods implemented by independent appraisers. As should be expected, the fair market value is generally larger than the full acquisition cost of the system to the developer. ${ }^{15}$ One can think of the difference as the profit margin for the investor/developer. ${ }^{16}$ Depending on the maturity of the solar residential market within a given state, this additional margin could be anywhere from 10\% (California) to 30\% (North Carolina). Accordingly, a reduction in the magnitude of the ITC will lead, ceteris paribus, to a higher percentage increase in the LCOE for residential systems.

\footnotetext{
${ }^{15}$ In their reports to investors, companies like SolarCity explicitly discuss the magnitude of their own installation cost in comparison to the fair market value of the systems they install (SolarCity, 2014).

${ }^{16}$ The corresponding mark-up is reflected in our parameter $\mu>1$ in Table A.1 in Appendix A (Supplementary Data). Further, Appendix B extends the LCOE formula to settings where the fair market value for tax purposes may differ from the system acquisition cost incurred by the developer/investor.
} 


\section{4 'Phasing-Down' the ITC}

The findings reported in Table 3 indicate that the magnitude of the anticipated ITC stepdown is likely to result in a 'cliff' for the U.S. solar industry in early 2017. At the same time, the sustained reduction in PV system costs demonstrated over many years suggests that solar energy will not require an indefinite continuation of the $10 \%$ ITC. An alternative to the current tax law could therefore specify a smoother glide path that would entail a complete elimination of the federal tax incentives at some definitive future date. This complete elimination feature introduces a quid-pro-quo element that could make alternative phase-down scenarios more acceptable politically.

For simplicity, we focus on a policy scenario with three distinct phases starting at the beginning of 2017, 2021 and 2025, respectively. For the first two phases, the revised tax rules would be targeted so as to result in LCOEs that are in between those corresponding to the $10 \%$, and the $30 \%$ ITC benchmarks. The impact of gradually reduced tax incentives would be partially offset by the anticipated cost reductions during the previous phase. These qualitative features of our alternative phase-down scenario are illustrated in Figure 2. Consistent with the glide path LCOE* (in red), the proposal would set the ITC such that all segments and geographies would be better off than they would have been at a 10\% ITC, but less well off than they would have been under the current 30\% ITC for the years 2017 - 2020. The proposed policy would then, at the end of the first four years, reduce the ITC, causing a 'seesaw' effect, albeit more muted than the one projected in 2017 under current policy. ${ }^{17}$ Finally, after another four years, the ITC would be reduced to zero beginning in 2025.

One way to front-load federal support for solar PV relative to the current tax rules would be to offer a 20\% ITC for the years 2017 - 2020, a 10\% ITC for the years 2021 - 2024 and zero thereafter. Clearly this would be in keeping with the above ideas for a gradual phasedown as illustrated by the LCOE* $^{*}$ path in Figure 2. An alternative policy would set the applicable ITC as a lump-sum dollar amount rather than a percentage of the system price. One argument in favor of a lump-sum amount is that because smaller residential systems tend to be the most expensive on a per Watt basis, the current solar ITC provides the largest support to residential PV systems in terms of dollars per Watt installed.

More flexible and targeted tax credits can be achieved by providing investors with a

\footnotetext{
${ }^{17}$ Obviously, the magnitude of the seesaw effect could be muted further by more frequent adjustments to the ITC schedule.
} 


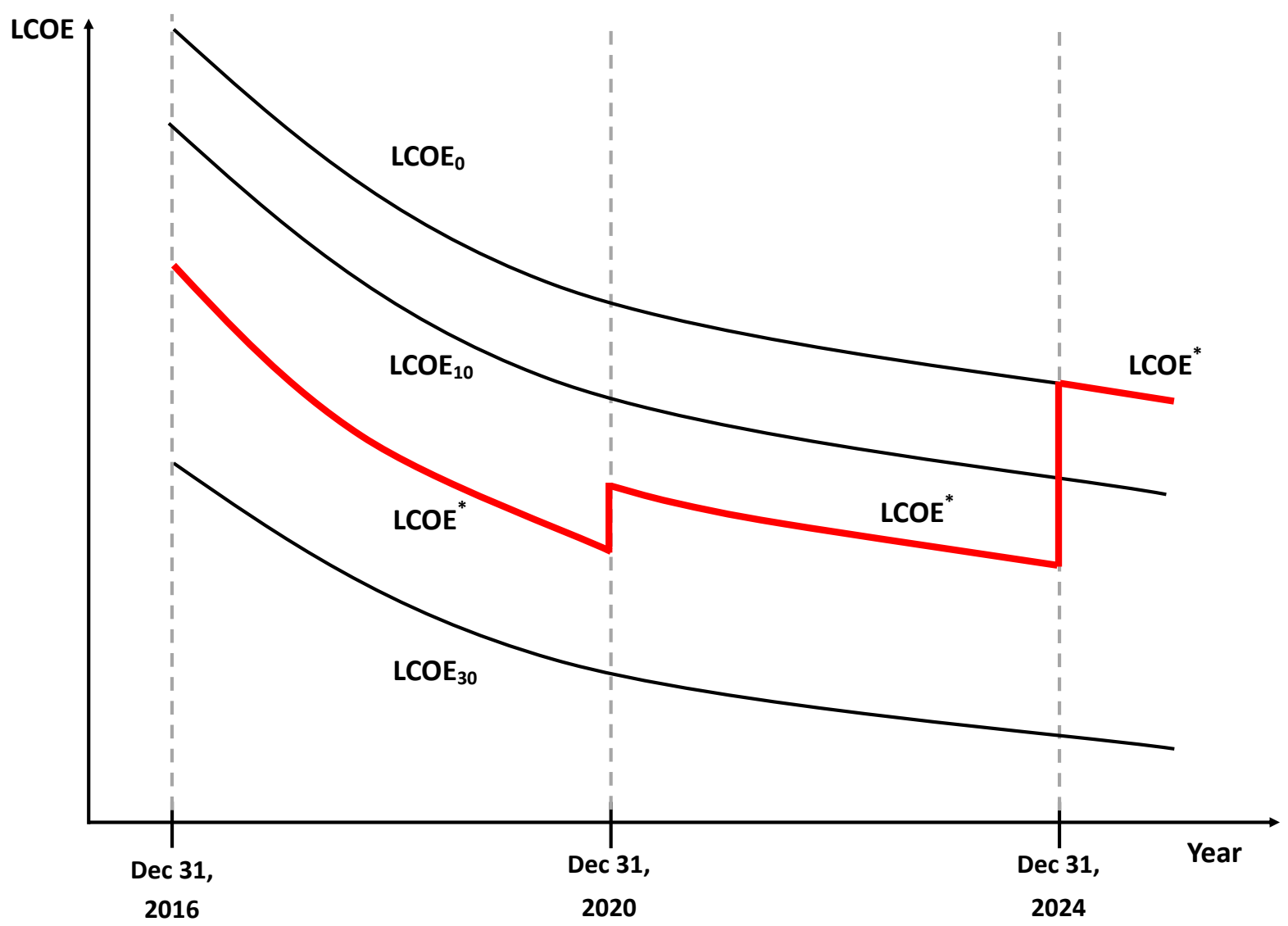

Figure 2: Glide path with 'seesaw' pattern and ultimate phase-out past 2024.

choice. Specifically, our phase-down scenario offers a choice between a $20 \%$ ITC or a lumpsum ITC in the amount of 35 cents per Watt installed for the years 2017 - 2020. Consistent with the overall concept of diminishing ITC support, the second phase would cut the previous parameters in half for the years 2021 - 2024. Investors in new facilities would then have the choice between a 10\% ITC or a lump-sum ITC in the amount of 17.5 cents per Watt. We refer to this policy alternative as the ITC Choice Scenario. ${ }^{18}$

The 35 cents per Watt installed figure can be calibrated by putting a value on the stream of future carbon emissions that would be avoided by generating power from solar

\footnotetext{
${ }^{18} \mathrm{An}$ additional consideration in determining how ITCs are calculated is that a percentage-based ITC amounts to cost sharing between the investor and the government. As a consequence, it provides only partial incentives to reduce costs, while a lump-sum ITC gives investors the full return on any cost reductions that the solar PV industry achieves.
} 
rather than fossil fuel energy resources. For instance, modern combined cycle natural gas generation facilities have a $\mathrm{CO}_{2}$ emissions rate of about $0.35 \mathrm{~kg}$ per $\mathrm{kWh}$. If one multiplies this emission rate with a 'shadow price' for carbon emissions sent into the atmosphere, one obtains the cost of avoided carbon emissions associated with one Watt of solar power. Such a calculation must take into consideration the useful life of the facility, the number of hours per year and the capacity factor of the solar facility. ${ }^{19}$ Combining these input variables, one arrives at the following lump-sum ITC $\left(\mathrm{ITC}_{L S}\right)$, calculated on a per Watt installed basis.

$$
I T C_{L S}=8,760 \mathrm{~h} / \text { year } \cdot C F \cdot T \cdot A E \cdot C C,
$$

where:

\section{$C F: \quad$ Average capacity factor (in \%)}

$T$ : Years of operation (in years)

$A E$ : Avoided $\mathrm{CO}_{2}$ emissions (in $\mathrm{kg}$ of $\mathrm{CO}_{2}$ per $\mathrm{kWh}$ )

$C C$ : Avoided cost of carbon (in $\$$ per tonne of $\mathrm{CO}_{2}$ ).

The initial 35థ/W installed figure underlying our ITC Choice scenario is obtained with the following parameter inputs: (i) the useful life of the solar facility ( $\mathrm{T}$ ) is equal to 20 years; (ii) the capacity factor $(\mathrm{CF})$ is $16 \%$; (iii) the imputed price of $\mathrm{CO}_{2}$ is $\$ 35$ per tonne ${ }^{20}$; and (iv) the avoided emissions are $0.35 \mathrm{~kg}$ per $\mathrm{kWh}$, as discussed above in connection with natural gas power plants. ${ }^{21}$ Interestingly, our results below show that offering investors an initial 35\&/W figure (half that figure for the years 2021 - 2024) would be consistent with the idea of diminished tax support relative to the benchmark of a 30\% ITC. In other words, the resulting levelized cost figures stay within the range envisioned for the $\mathrm{LCOE}^{*}$ curve in Figure 2.

Tables $4-7$ display our results. As indicated in the captions to the tables, we project

\footnotetext{
${ }^{19}$ Unlike the calculation for the unit capacity cost of solar installation in equation (2), we do not discount future avoided emissions because $\mathrm{CO}_{2}$ emissions are projected to stay in the atmosphere for about a century and therefore timing is almost inconsequential.

${ }^{20}$ According to the EPA and various integrated assessment models, the $\$ 35$ per tonne figure is in the mid-range of various estimates of the social cost of one tonne of carbon dioxide emitted into the atmosphere (Interagency Working Group on Social Cost of Carbon, United States Government, 2013).

${ }^{21}$ One may ask why our phase-down scenario calls for a lump-sum that ITC that is decreasing over time, even though the avoided cost of carbon arguably is not. Our specification here is subordinated to the idea that, in future years there would be a price of carbon dioxide, however in order to be palatable politically, its value may be lower than what is suggested by an integrated assessment model.
} 
the levelized cost of new solar installations for a $30 \%$ and a $10 \%$ ITC with the red and blue bars, respectively. The results for our ITC Choice Scenario are shown in purple bars. For direct comparison, we also show in green bars the findings that would obtain for a simpler ITC phase-down policy that would not allow for a lump-sum choice but simply offer fixed percentages of $20 \%$ starting in $2017,10 \%$ starting in 2021 and zero thereafter. This scenario is referred to as the 20/10/0 Scenario. By construction, the purple bars can never exceed the green ones and a positive difference indicates that the investing party would be better off with a lump-sum ITC. 

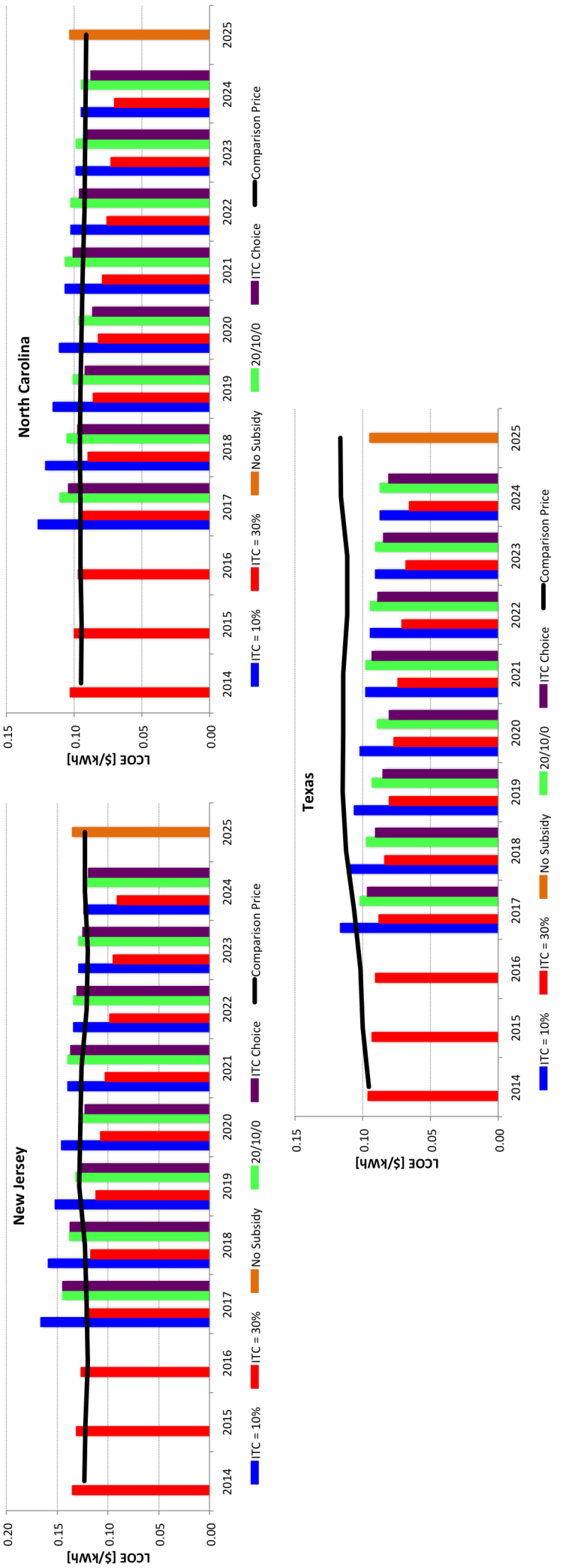

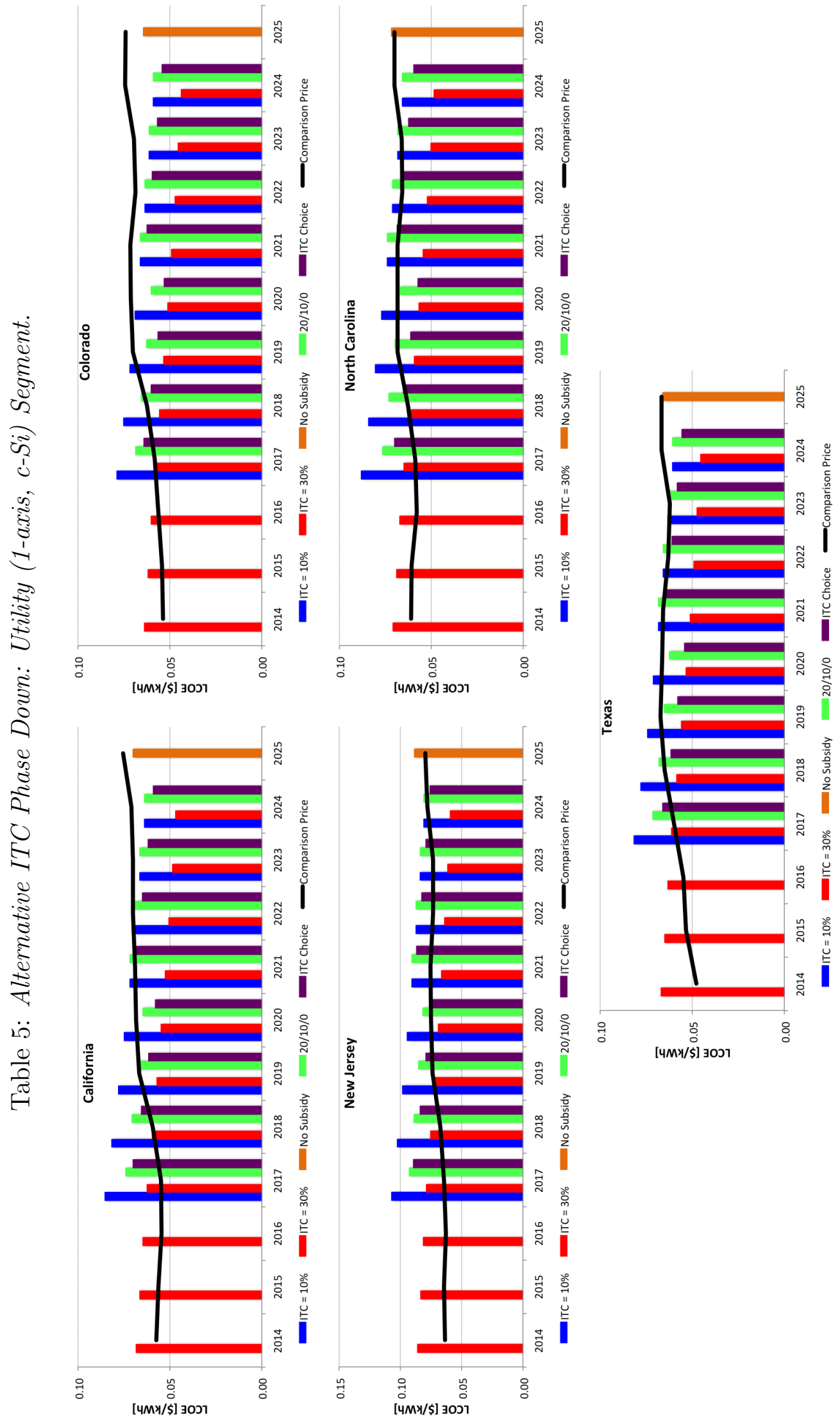

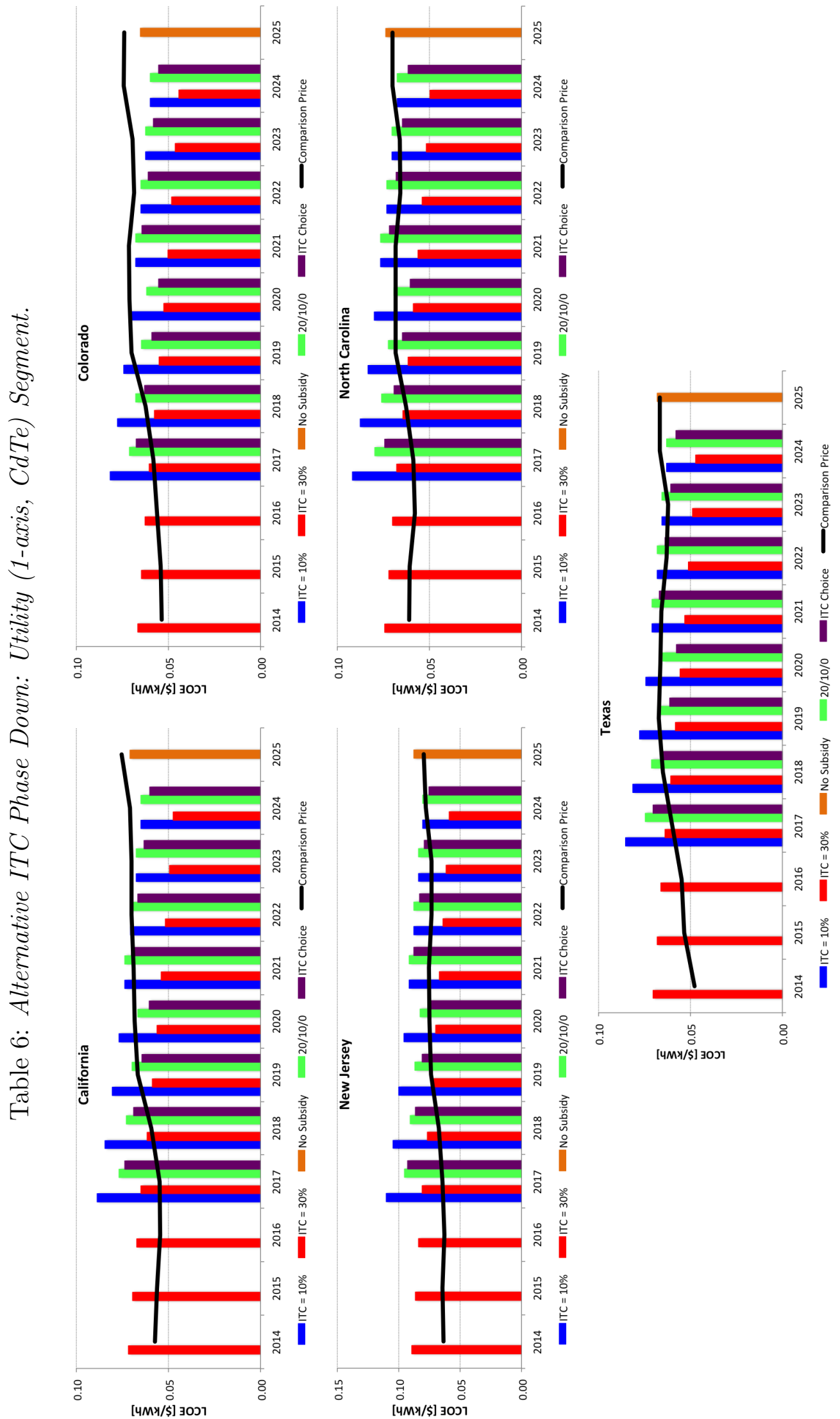

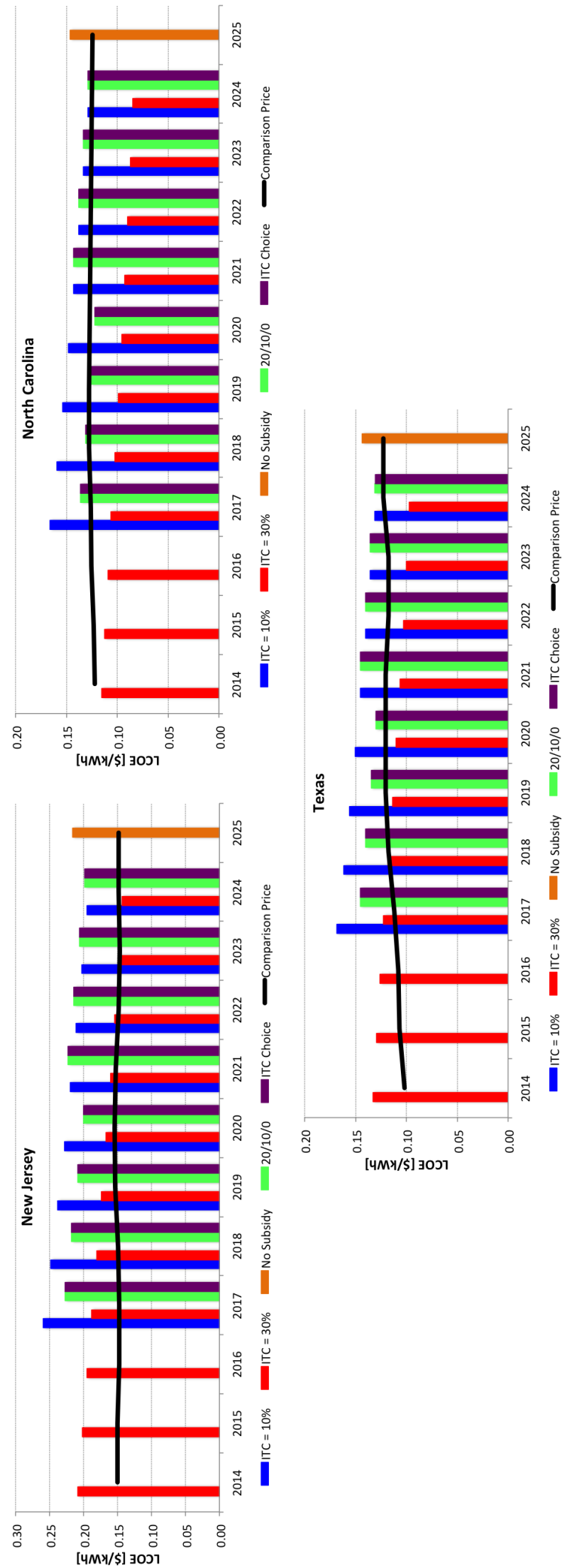


\section{Discussion}

The bar graphs in Tables $4-7$ show that our ITC phase-down proposal results in levelized cost figures are consistent with the conceptual approach in Figure 2. In terms of their levelized cost figures, all segments would be worse-off for the years 2017 - 2020 in comparison to the $30 \%$ ITC benchmark, though they would also be substantially better positioned than under a 10\% ITC. Relative to the 10\% ITC benchmark, the residential segment would gain the most under our proposal on a cents per $\mathrm{kWh}$ basis for the years $2017-2020$. The commercial and utility-scale segments would continue to benefit from our phase-down proposal for the years 2021 - 2024. Taken together, our results indicate that phasing-down the ITC on these terms would go a long way towards mitigating the sharp jump in the LCOE that is likely to result if the tax rules were to change as currently scheduled.

Table 4 summarizes the findings for the commercial-scale segment. In all five sample states, the ITC Choice Scenario is the more attractive alternative as evidenced by the fact the purple bars are below the green ones. Because system prices for commercial-sized installations tend to be smaller in comparison to residential-sized systems, commercial investors would prefer the lump-sum ITC of 35\$/W (half that value past 2020). With this option, commercial-scale installations would be "comfortably competitive" in California and Texas and close to break-even in the remaining three states of Colorado, New Jersey and North Carolina during the period 2017 - 2024. By 2025, and without any ITC, commercial installations in California and Texas are projected to be competitive, at break-even in Colorado, and at a small disadvantage in New Jersey and North Carolina.

The results for the utility-scale segment are displayed in Tables 5 and 6 for crystalline silicon (c-Si) and thin film (CdTe), respectively. Like the commercial segment, the ITC Choice Scenario would induce utility-scale installations to opt for an ITC of $35 \mathrm{c} / \mathrm{W}$ (half that value past 2020). With this option, the LCOE of utility-scale installations is then projected to be competitive with wholesale electricity prices by 2018 in all five sample states, except for New Jersey. Furthermore, for these four states, utility-scale installations are projected to be competitive without any ITC by 2025. This finding reflects the expectation that the comparison prices, that is, the average wholesale price, will rise in real terms in all five states.

Finally, Table 7 exhibits our findings for the residential segment. Because this segment has the highest system prices per Watt installed, investors would opt for a $20 \%$ ITC (10\% past 2020) over a fixed $35 \mathrm{c} / \mathrm{W}$ (half that value past 2020). We note that the additional $10 \%$ 

in California, Colorado and North Carolina for the years 2017 - 2020. For the years 2021 2024, our numbers indicate that residential installations would have LCOEs that are within $10-20 \%$ of the applicable retail rate in all of the states except for New Jersey. Beyond 2024, however, residential solar installations are projected to face "head-winds" across the board, if the federal ITC support were indeed to be eliminated entirely by the end of 2024 and no new state programs were to be enacted. This prediction reflects the the EIA's (2014) forecast that, in contrast to wholesale prices, residential retail rates will either stay constant or decrease in real terms over the next decade.

Our analysis has derived a set of point estimates regarding the effectiveness of an alternative ITC policy, based on several working assumptions regarding the future progression of the solar PV industry. We now conduct a partial sensitivity analysis focused on two key variables: the rate of improvement in the price of solar PV systems and the applicable cost of capital. The spreadsheet model included as part of the Supplementary Data allows readers to perform additional robustness checks for other variables in the model.

As demonstrated in Sections $2-4$, the system price is by far the dominant LCOE component. Figure 3 examines the sensitivity of the LCOE to the assumed improvement rate for system prices. Assuming further the anticipated step-down in the ITC from $30 \%$ to $10 \%$ in early 2017, the plots in Figure 3 show the LCOE trajectory for three representative state/segment combinations. From left to right, the plots pertain to Colorado residential, North Carolina commercial and California utility solar energy systems. In each plot, the baseline LCOE trajectory (blue bar) is compared to the LCOE trajectories that are obtained when the overall average annual system price reduction rates are set either more conservatively (red bar) or more aggressively (green bar). The conservative scenario assumes a rate of improvement that is one percent less than baseline, while the more favorable green line assumes a one percent higher than the baseline improvement rate.

Due to compounding, the difference between the corresponding LCOE figures must widen over time. Nonetheless, the examples show that a $1 \%$ difference in the annual cost reduction rate in the system price leads approximately to a cumulative $7-10 \%$ change in the LCOE over the entire decade. From that perspective, our policy conclusions appear fairly robust with regard to the rate of expected cost improvements. Similar results emerge for the other state/segment combinations considered in our analysis. 

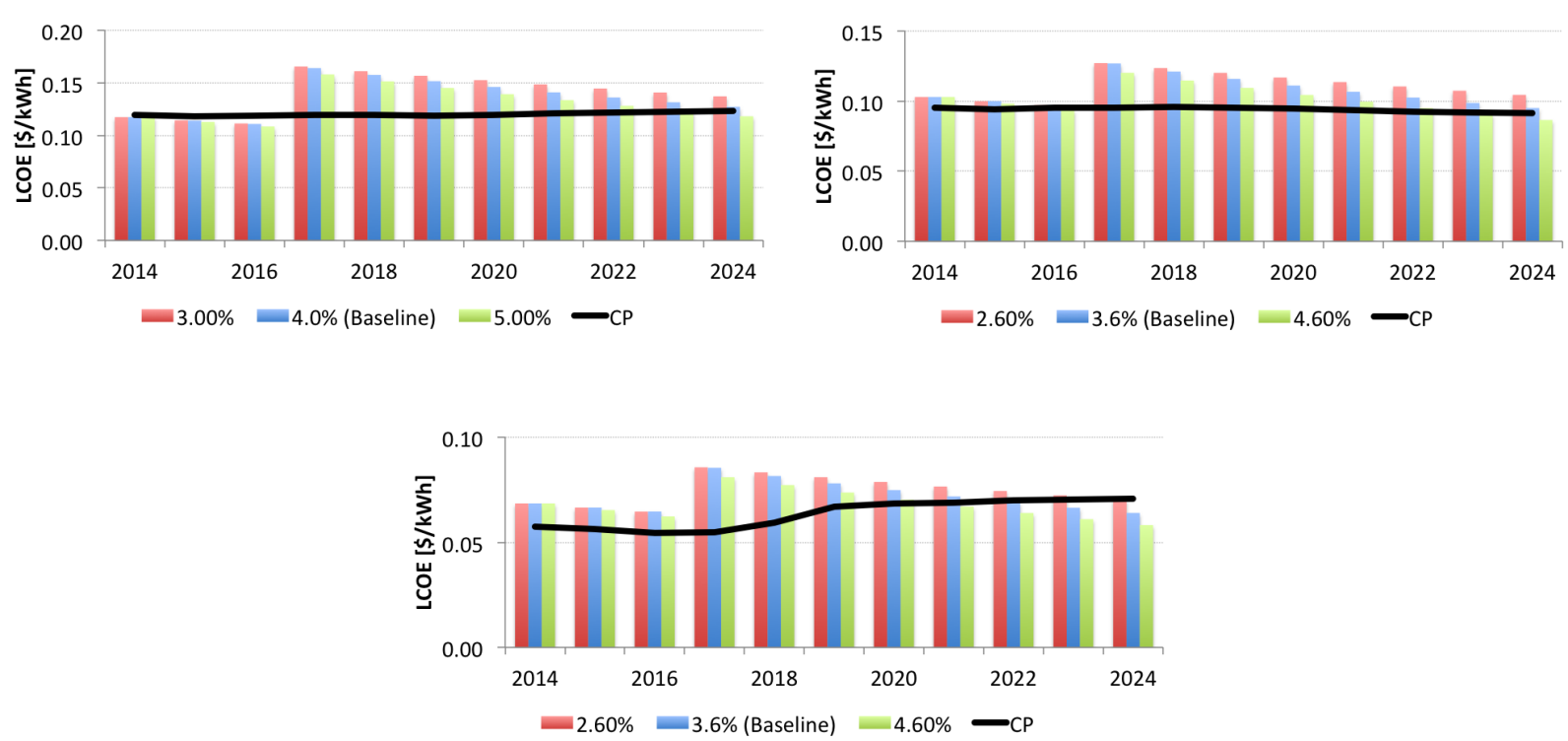

Figure 3: Sensitivity of LCOE to improvement rate in system price. From left to right: Colorado residential, North Carolina commercial, California utility scale.

Figure 4 confirms that the LCOEs for solar installations are sensitive to the assumed cost of capital, owing to the fact that upfront capital expenditures account for a large share of the overall cost (Ardani et al., 2013; Lazard, 2014; BNEF, 2015). For instance, the LCOE for utility scale installations in California decreases from 6.85 to $6.20 \mathrm{\phi} / \mathrm{kWh}$ in 2014 , as the assumed cost of capital drops from 7.5 to $6.5 \%$. As a general rule of thumb, an increase in the cost of capital by one percentage point triggers approximately a $10 \%$ increase in the corresponding LCOE.

With regard to the overall conclusion of our study, Figure 4 indicates that even with a substantially lower cost of capital the anticipated step down in the ITC at the end of 2016 would make solar PV at least temporarily uncompetitive for the sample applications considered here. With a lower cost of capital, the alternative phase-down scenario described above would even be more effective in keeping solar PV at least close to competitive levels.

Finally, it can be verified that our findings change predictably if one were to change several of the preceding parameters simultaneously. The corresponding graphs that are obtained for joint sensitivity tests are shown in a separate tab of our spreadsheet model as part of the Supplementary Data. 

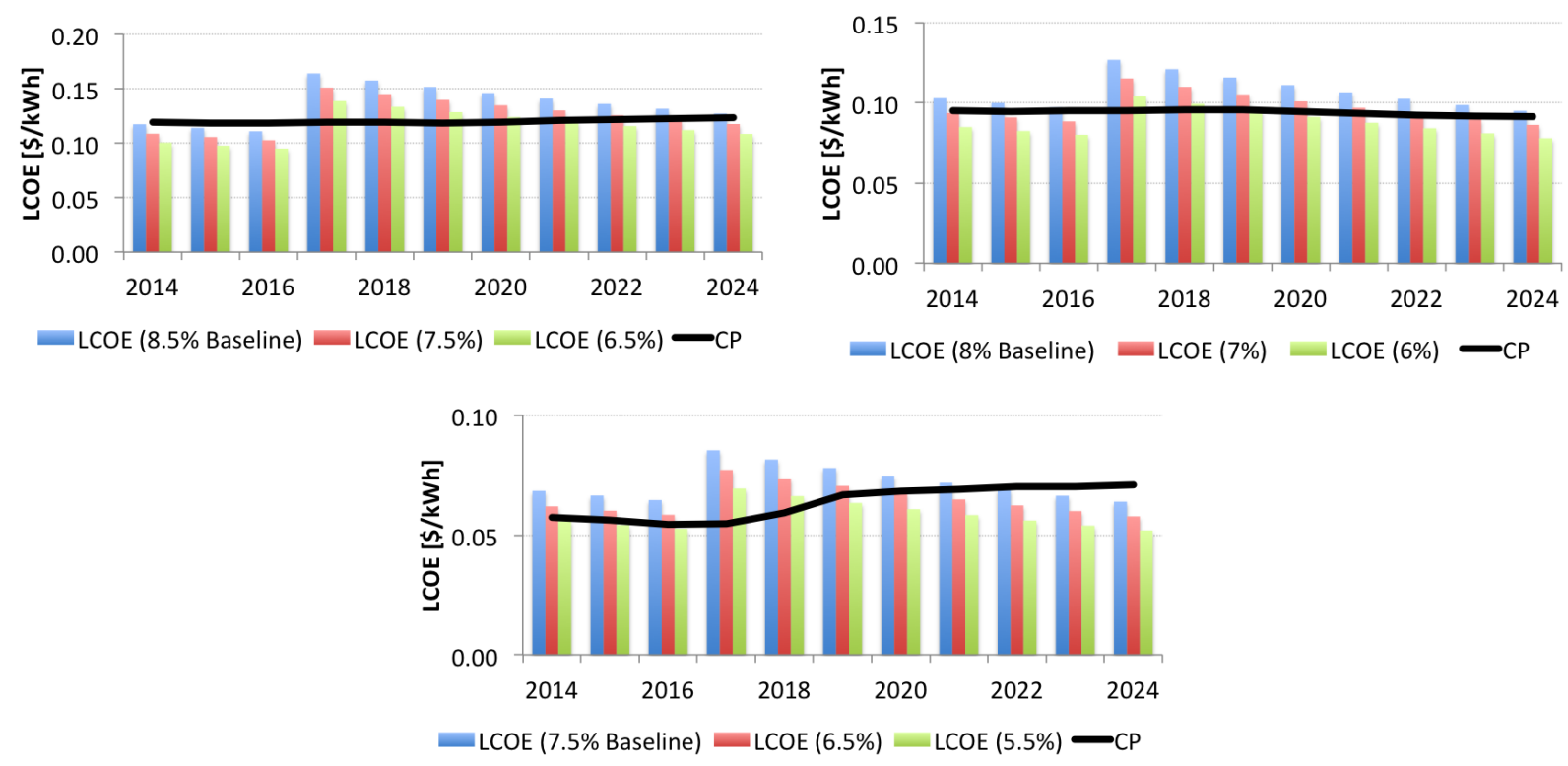

Figure 4: Sensitivity of LCOE to assumed cost of capital. Current incentive policy shown for representative state/segments. From left to right: Colorado residential, North Carolina commercial, California utility scale.

\section{Concluding Remarks}

Current federal tax policy stipulates that at the beginning of 2017 the ITC for solar energy systems in the U.S. will drop from $30 \%$ to 10\%, and remain at that level indefinitely. Our analysis has identified and evaluated an alternative policy scenario that would front-load federal tax support to the years 2017 - 2024, but in return eliminate the ITC for solar energy in its entirety post 2024. The main rationale for our alternative policy scenario is that the global solar PV industry continues to experience significant cost reductions and is poised to achieve "grid parity" within a decade. A sharp $20 \%$ decline in the ITC would likely result in a cliff at the beginning of 2017, yet federal tax support would continue indefinitely in years when it probably would no longer be needed.

Our analysis has evaluated the cost-competitiveness of solar energy systems across the three major segments of the solar PV industry in five sample states which collectively account for more than $65 \%$ of all solar capacity installations in the U.S. To project the impact of alternative tax policies, we have specified a dynamic that forecasts the reductions in solar system prices as a function of time. While our calculations are based on the assumption of continued and significant reductions in system prices and corresponding LCOE figures, we 
nonetheless conclude that an ITC step-down to $10 \%$ by early 2017 would render solar PV uncompetitive across the entire spectrum of applications considered in our study.

The alternative phase-down scenario examined in this paper would provide investors with a choice between an ITC calculated as either $20 \%$ of the system price or a lump-sum 35 cents per Watt for the years 2017 - 2020. This flexibility allows for more targeted incentives, as residential systems are likely to opt for the percentage-based ITC, while commercial- and utility-scale projects are likely to prefer the lump-sum tax credit. By phasing these incentives down by half, respectively, for the years 2021 - 2024, the resulting schedule of tax credits leads to LCOE figures that are in between those corresponding to the $10 \%$ and $30 \%$ ITC benchmarks.

Our findings indicate that for most of the applications considered here the diminishing ITC support would be just sufficient to sustain the cost competitiveness and current momentum of the solar industry. Furthermore, our numbers project that for most segments and locations the industry would be well positioned past 2024, even though our proposal envisions the complete elimination of the ITC in exchange for stronger incentives during the early phase from $2017-2020$.

There are several promising avenues for extending the analysis in this paper. As noted in Section 2, the basic LCOE concept does not account for synergies between real-time electricity prices and the daily pattern of power generation by solar systems. Building on existing frameworks, it would be useful to quantify the magnitude of any synergistic effects for different locations. In future work, it would also be useful to refine the dynamic of future reductions in solar PV system prices, taking particularly into consideration that some components of the BOS costs are likely to change not only as a function of time but also the actual trajectory of new deployments in a particular location. Finally, our analysis has not attempted to "score" the alternative phase-down proposal in terms of tax revenues foregone by the U.S. Treasury. The general trade-off here will be between lower tax revenues up to 2024 in exchange for permanent savings thereafter. 


\section{References}

Ardani, K., D. Seif, R. Margolis, J. Morris, and C. Davis (2013), "Non-Hardware (Soft) Cost-Reduction Roadmap for Residential and Small Commercial Solar Photovoltaics," Tech. rep., National Renewable Energy Laboratory, nREL/TP-7A40-59155.

Barbose, G. L., S. Weaver, and N. R. Darghouth (2014), "Tracking the Sun VII: An Historical Summary of the Installed Price of Photovoltaics in the United States from 1998-2013," Tech. rep., Lawrence Berkeley National Laboratory.

BNEF (2014), "Bloomberg New Energy Finance Inverter Price Index," https://surveys . bnef.com/solar/inverter-index.

BNEF (2015), "America Insight: US Solar Opens Up the Throttle," Conference call presentation by Nicholas Culver given on January 28, 2015 to UBS.

Branker, K., M. Pathak, and J. Pearce (2011), "A review of solar photovoltaic levelized cost of electricity," Renewable and Sustainable Energy Reviews, 15(9), 4470 - 4482, doi:http:// dx.doi.org/10.1016/j.rser.2011.07.104, URL http://www.sciencedirect.com/science/ article/pii/S1364032111003492.

Comello, S., and S. Reichelstein (2014), "Incentives for early adoption of carbon capture technology," Energy Policy, 74(0), 579 - 588, doi:http://dx.doi.org/ 10.1016/j.enpol.2014.09.003, URL http://www.sciencedirect.com/science/article/ pii/S0301421514004947.

del Ro, P., and P. Mir-Artigues (2012), "Support for solar $\{$ PV $\}$ deployment in Spain: Some policy lessons," Renewable and Sustainable Energy Reviews, 16(8), 5557 - 5566, doi:http:// dx.doi.org/10.1016/j.rser.2012.05.011, URL http://www.sciencedirect.com/science/ article/pii/S1364032112003395.

DSIRE (2014a), "Database of State Incentives for Renewables and Efficiency, California Incentives," URL http://dsireusa.org/incentives/index. cfm?re=0\&ee=0\&spv=0\&st= $0 \& \operatorname{srp}=1 \&$ state $=$ CA.

DSIRE (2014b), "Database of State Incentives for Renewables and Efficiency, Colorado Incentives," URL http://dsireusa.org/incentives/index. $c f m$ ?re=0\&ee=0\&spv=0\&st= $0 \& \operatorname{srp}=1 \&$ state $=$ CO. 
DSIRE (2014c), "Database of State Incentives for Renewables and Efficiency, New Jersey Incentives," URL http://dsireusa.org/incentives/index.cfm?re=0\&ee=0\&spv= $0 \& s t=0 \& s r p=1 \&$ state $=$ NJ.

DSIRE (2014d), "Database of State Incentives for Renewables and Efficiency, North Carolina Incentives," URL http://dsireusa.org/incentives/index. cfm?re=0\&ee=0\&spv= 0\&st $=0 \& \operatorname{srp}=1 \&$ state $=$ NC.

DSIRE (2014e), "Database of State Incentives for Renewables and Efficiency, Texas Incentives," URL http://dsireusa.org/incentives/index. cfm?re=0\&ee=0\&spv=0\&st= O\&srp $=1 \&$ state $=\mathrm{TX}$.

EIA (2014), "National Energy Modeling System run REF2014.D102413A for the Annual Energy Outlook 2014 with Projections to 2040, DOE/EIA-0383(2014)," Tech. rep., U.S Energy Information Agency (EIA), Washington, DC.

Feldman, D., G. L. Barbose, R. Margolis, T. James, S. Weaver, N. R. Darghouth, R. Fu, C. Davidson, S. Booth, and R. H. Wiser (2014), "Photovoltaic System Pricing Trends: Historical, Recent, and Near-Term Projections - 2014 Edition," Tech. rep., National Renewable Energy Laboratory, nREL/PR-6A20-62558.

Ferioli, F., and B. C. C. van der Zwaan (2009), "Learning in Times of Change: A Dynamic Explanation for Technological Progress," Environmental Science $\&$ Technology, 43(11), 4002-4008, doi:10.1021/es900254m.

Goodrich, A., T. James, and M. Woodhouse (2012), "Residential, commercial, and utility scale photovoltaic (PV) system prices in the United States: current drivers and costreduction opportunities," Tech. rep., National Renewable Energy Laboratory, nREL/TP6A20-53347.

GTM Research (2014), "GTM Research Global PV Balance of Systems Landscape 2014 (Forthcoming)," Tech. rep., GTM Research Inc., Boston, MA.

Hernandez-Moro, J., and J. Martnez-Duart (2013), "Analytical model for solar \{PV\} and $\{\mathrm{CSP}\}$ electricity costs: Present $\{\mathrm{LCOE}\}$ values and their future evolution," Renewable and Sustainable Energy Reviews, 20, 119 - 132, doi:http://dx.doi.org/10. 
1016/j.rser.2012.11.082, URL http://www.sciencedirect.com/science/article/pii/ S136403211200696X.

Interagency Working Group on Social Cost of Carbon, United States Government (2013), "Technical Update of the Social Cost of Carbon for Regulatory Impact Analysis - Under Executive Order 12866," Tech. rep., Interagency Working Group on Social Cost of Carbon, United States Government, Washington, DC.

Jordan, D., J. Wohlgemuth, and S. Kurtz (2012), "Technology and Climate Trends in PV Module Degradation," Tech. rep., National Renewable Energy Laboratory, nREL/CP$5200-56485$.

Joskow, P. (2011), "Comparing the Costs of Intermittent and Dispatchable Electricity Generating Technologies," American Economic Review Papers and Proceedings, 100(3), 238 241.

Laird, F. N., and C. Stefes (2009), "The diverging paths of German and United States policies for renewable energy: Sources of difference," Energy Policy, 37(7), 2619 - 2629, doi: http://dx.doi.org/10.1016/j.enpol.2009.02.027, URL http://www.sciencedirect.com/ science/article/pii/S0301421509001189.

Lazard (2014), "Levelized Cost of Energy Analysis - Version 8.0," Tech. rep., Lazar Capital Markets Report, version 8.

Liou, H. M. (2015), "Comparing feed-in tariff incentives in Taiwan and Germany," Renewable and Sustainable Energy Reviews, 50, 1021 - 1034, doi:http://dx.doi.org/10. 1016/j.rser.2015.05.009, URL http://www.sciencedirect.com/science/article/pii/ S1364032115004670.

Lux Research (2013), "The Squeeze: Trends in Solar Balance of Systems," Available by subscription to Lux Research.

Moore, L. M., and H. N. Post (2008), "Five years of operating experience at a large, utilityscale photovoltaic generating plant," Progress in Photovoltaics: Research and Applications, 16(3), 249-259, doi:10.1002/pip.800, URL http://dx.doi.org/10.1002/pip.800. 
Neij, L. (2008), "Cost development of future technologies for power generationA study based on experience curves and complementary bottom-up assessments," Energy Policy, 36(6), 2200 - 2211, doi:http://dx.doi.org/10.1016/j.enpol.2008.02.029, URL http: //www.sciencedirect.com/science/article/pii/S0301421508001237.

Nemet, G. F. (2006), "Beyond the Learning Curve: factors influencing cost reductions in photovoltaics," Energy Policy, 34, 3218 - 3232.

NREL (2014), "PVWatts Calculator for Overall DC to AC Derate Factor," http://rredc. nrel.gov/solar/calculators/pvwatts/version1/derate.cgi.

Reichelstein, S., and A. Sahoo (2015a), "Cost-and Price Dynamics of Solar PV Modules," Working paper, March, Stanford Graduate School of Business.

Reichelstein, S., and A. Sahoo (2015b), "Time of day pricing and the levelized cost of intermittent power generation," Energy Economics, 48(0), 97 - 108, doi:http://dx.doi.org/ 10.1016/j.eneco.2014.12.005, URL http://www.sciencedirect.com/science/article/ pii/S0140988314003211.

Reichelstein, S., and M. Yorston (2013), "The Prospects for Cost Competitive Solar PV Power," Energy Policy, 55, 117 - 127.

RSMeans (2014), "Building Construction Cost Data," Tech. rep., Reed Construction Data, Norwell, MA.

SNL Financial (2014), "Regional Power Market Summaries," Available by subscription to SNL Financial.

SolarCity (2014), "Delivering Better Energy: Investor Presentation," http://files . shareholder . com/downloads/AMDA-14LQRE/0x0x664578/ add6218d-90ec-4089-9094-4259533d473e/SCTY_Investor_Presentation.pdf.

Swanson, R. (2011), "The Silicon Photovoltaic Roadmap," The Stanford Energy Seminar.

Tyagi, V., N. A. Rahim, N. Rahim, and J. A. Selvaraj (2013), "Progress in solar $\{P V\}$ technology: Research and achievement," Renewable and Sustainable Energy Reviews, 20, 443 461, doi:http://dx.doi.org/10.1016/j.rser.2012.09.028, URL http://www . sciencedirect. com/science/article/pii/S1364032112005291. 